\title{
New model for performance prediction in fixed-bed reactors based on the approach of the unused bed zone
}

\author{
P.N. Fanfan ${ }^{1}$, N. Mabon ${ }^{1}$, I. Carletti ${ }^{2}$, J.J. Claustriaux ${ }^{2}$, P. Thonart ${ }^{3}$, G. Lognay ${ }^{1}$, A. Copin ${ }^{1}$, J.P. Barthelemy ${ }^{1}$ \\ ${ }^{1}$ Department of Analytical Chemistry, Gembloux Agricultural University (FUSAGx), 2, Passage des Déportés, B5030 Gembloux, Belgium. \\ 2 Department of Applied Statistics and Mathematics, Gembloux Agricultural University (FUSAGx), 2, Passage des Déportés, B5030 Gembloux, \\ Belgium \\ ${ }^{3}$ Centre Wallon de Biologie Industrielle (CWBI), 2, Passage des Déportés, B5030 Gembloux, Belgium.
}

\begin{abstract}
In the present study a practical model useful for designers dealing with pilot scale reactors for pollutant control has been developed. Investigations were undertaken for a single-component lead study on New Zealand clinoptilolite at the temperature of $25 \pm 1{ }^{\circ} \mathrm{C}$. Fifteen runs under different operating conditions such as particle characteristics (expressed as $d_{\mathrm{p}}{ }^{*} / D$ ), column geometry (as $l^{*} / D$ ) and flow speed (as $R_{e}{ }^{*}$ ) have been performed. The results were interpreted by a response surface method (RSM) from which an equation giving the unused bed zone (UBZ) was obtained. From those dimensionless parameters, a sequence of contour plots was drawn, making it easy for a designer to choose optimum design parameters while controlling the operation performance. The flow rate $\left(R_{e}{ }^{*}\right.$ range was established over the laminar flow conditions from 1 to $8,\left(l / D^{*}\right)$ was extended from 7 to 20 and $\left(d_{\mathrm{p}} / D^{*}\right)$ varied from $3 \%$ to $10 \%$. Optimization of performance of the reactor as UBZ could vary from $10 \%$ to $40 \%$ of the material operating capacity.
\end{abstract}

Keywords: Modeling - fixed-bed reactors (FBR) - unused bed zone (UBZ) - natural zeolite - lead removal.

\section{INTRODUCTION}

Parameters related to the operation through a fixed-bed reactor, such as particle diameter, flow speed and column geometry (column length and diameter) have been widely studied (Chen and Wang, 2004; Hlaway et al., 1982). Previous studies have highlighted that too fine a particle size drives to excessive head losses, pore clogging by dust formation (Zorpas et al., 2002) while, on the other hand, too large particle diameters drive to a weak bed density responsible for preferential path and partial wetting of the material (Pansini, 1996). Basically, the flow must be chosen in order to favor an optimal contact time between mobile and stationary phases. Most authors expressed this parameter in bed volume per hour (BV/h). Pansini (1996) recommended 7BV/h for fixed-bed operation, while Inglezakis and Grigoropoulou (2003) recommend a range between 5 and $15 \mathrm{BV} / \mathrm{h}$. The column geometry is often expressed as the $l / D$ ratio which, according to general principles of chromatography, must range between 10 and 20. For small diameter columns it is important to minimize wall effects where the solution will have the tendency to flow along the inner wall, driving to a partial wetting of the material. Inczedy (1966) suggests the column diameter on particle diameter $(D / d)$ ratio to be taken from 10 in order to avoid inner wall effect. Inglezakis and Grigoropoulou (2004) have widely studied the influence of such parameters, and they have given sets of values in order to optimize operations in fixed-bed columns, but these values are not given in a systematic "easy to use" way. Several mathematical models exist, from highly sophisticated to simplified ones (Hashimoto et al., 1977; Crittenden and Weber, 1978). These models have been subjected to critical discussions and do not often furnish satisfactorily results (Inglezakis and Grigoropoulou, 2001; Iordanidis et al., 2003). Besides these models, empirical ones which are still much employed and give good results, especially when rigorous mathematical parametrization is not important (Lau et al., 2004). The aim of this study is to define a simplified model to predict breakthrough curves and evaluate column operation performance on the basis of dimensionless parameters. This model should, at the same time, give opportunities to draw industrial scale fixed-bed reactors for pollutant control.

\section{THEORETICAL}

The cationic exchange phenomenon may be interpreted as the result of simultaneous combination of two different phenomena. They can be defined as a mechanical dispersion of the fluid through the porous material and an ionic diffusion through pores to the exchange sites (Bear, 1972; Daugherty et al., 1985). If the first is governed by internal geometry of the material and flow dispersion, the second one, on the other hand, is completely regulated by the randomness of molecular diffusion (Bear, 1972). Moreover, several authors have come to the conclusion that at lower Reynolds number $\left(R_{\mathrm{e}}\right)$ values, the main factor to affect the breakthrough curves is the longitudinal dispersion 
coefficient, $D_{\mathrm{L}}$ (Suzuki, 1994; Miyake and Suzuki, 1993; Guo-Hua and Ping, 2000). The latter is considered as the contribution of molecular diffusion and dispersion caused by the fluid flow (Suzuki, 1990), as in the following :

$D_{\mathrm{L}}=D_{\mathrm{L}, \text { molecular }}+D_{\mathrm{L}, \text { Flow. }}$

Considering only the second parameter (Ceteris-paribus principle), it is possible to come to an optimization of the operation in fixed-bed reactors, from the optimization of dispersion caused by the fluid flow.

In other words, we assume that the shape of breakthrough curves depends uniquely on physical properties bound to the flow and column geometry. The problem to be solved is part of the fluid mechanical domain and may be interpreted as follows. The physical phenomenon under study corresponds to a fluid (viscosity $\eta$, density $\rho_{1}$ ) passing through a bed of porous material with particle diameter $\left(d_{\mathrm{p}}\right)$ and density $\left(\rho_{\mathrm{p}}\right)$. The material has been previously packed in a column whose length is $(l)$ and diameter $(D)$. The flow is operated at the speed $(u)$ and the attended response is the unused bed zone (UBZ). In the whole breakthrough curve, UBZ, as defined elsewhere (Lau et al., 2004, Pansini 1996), is a good parameter for performance evaluation in fixed reactors. UBZ is the surface comprised between the breakthrough point and saturation point. From a practical point of view, UBZ is part of the material, which remained unused after breakthrough occurs and the operator stopped the operation. It is expressed as a percentage of the total breakthrough curve which represents the total operating capacity. The first relation may therefore be assumed as

$\mathrm{UBZ}=f\left(\eta, \rho_{1}, d_{\mathrm{p}}, \rho_{\mathrm{p}}, l, D, u\right)$.

Applying dimensional analysis to the above relation (Ouziaux and Perrier, 1978), with the Vaschy-Bucking-ham's theorem we obtain $n-p$ dimensionless variables such as

$$
F(\pi 1, \pi 2, \pi 3, \ldots, \pi n-p)=0
$$

with $n$ being the number of parameters of the equation and $p$, the number of fundamental units.

The direct method (Daugherty et al., 1985) allows one to determine these dimensionless parameters. The studied variables are reported in Table 1 . The variable UBZ being already dimensionless, has not been taken into account.

Let $D, \rho_{1}, u$ be fundamental values from which the others will be drawn.

Table 2 gives the expression of the dimensionless parameters: the first relation, its dimensional equation form and its final solution.

From this table we can conclude that UBZ is a function of these parameters, as expressed in the following relation

$$
\mathrm{UBZ}=f\left(R_{e}, \frac{d_{\mathrm{p}}}{D}, \frac{\rho_{\mathrm{p}}}{\rho_{1}}, \frac{l}{D}\right) .
$$

Table 1. Parameters, dimensions and symbols.

\begin{tabular}{lll}
\hline Variables & Symbols & Dimension \\
\hline Column diameter & $\mathrm{D}$ & $\mathrm{L}$ \\
Solution dynamic viscosity & $\eta$ & $M L^{-1} T^{-1}$ \\
Solution density & $\rho_{1}$ & $M L^{-3}$ \\
Particles diameter & $d_{\mathrm{p}}$ & $\mathrm{L}$ \\
Material density & $\rho_{\mathrm{p}}$ & $M L^{-3}$ \\
Flow speed & $u$ & $L T^{-1}$ \\
Column length & $l$ & $\mathrm{~L}$ \\
\hline
\end{tabular}


Table 2. Expression of the dimensionless parameters.

\begin{tabular}{|c|c|c|}
\hline First relation & Dimensional equation & Solution \\
\hline $\begin{array}{l}\pi 1=\mathrm{UBZ} \\
\pi 2=\frac{\eta}{D^{\alpha 2} \rho^{\beta 2} \mu^{2}{ }^{2}}\end{array}$ & $M L^{-1} T^{-1}=L^{\alpha 2}\left(M L^{-3}\right)^{\beta 2}\left(L T^{-1}\right)^{\gamma 2}$ & $\begin{array}{l}\pi 1=\mathrm{UBZ} \\
\pi 2=\frac{\eta}{D \rho_{1} u}=\frac{1}{R_{e}}\end{array}$ \\
\hline$\pi 3=\frac{d_{p}^{2}}{D^{\alpha 3} \beta_{1}^{\beta 3} u l^{3}}$ & $L=L^{\alpha 3}\left(M L^{-3}\right)^{\beta 3}\left(L T^{-1}\right)^{\gamma^{3}}$ & $\pi 3=d_{\mathrm{p}} / D$ \\
\hline$\pi 4=\frac{\rho_{p}^{\beta}}{D^{\alpha 4} \rho^{\beta, u^{4}}}$ & $M L^{-3}=L^{\alpha 4}\left(M L^{-3}\right)^{\beta 4}\left(L T^{-1}\right)^{p 4}$ & $\pi 4=\rho_{\mathrm{p}} / \rho_{1}$ \\
\hline$\pi 5=\frac{1}{D^{\alpha 5} \rho_{p}^{\beta n_{2} \eta^{5}}}$ & $L=L^{\alpha 5}\left(M L^{-3}\right)^{\beta 5}\left(L T^{-1}\right)^{\gamma 5}$ & $\pi 5=l / D$ \\
\hline
\end{tabular}

If we consider $\rho_{\mathrm{p}} / \rho_{1}$, the ratio of the material density on the liquid density, constant for a given material and given solution, the above relation becomes

$$
\mathrm{UBZ}=f\left(R_{e}, \frac{d_{\mathrm{p}}}{D}, \frac{l}{D}\right)
$$

The above relation shows that it is possible to draw a mathematical expression giving the UBZ value for a given operation in fixed-bed reactors from flow parameters $\left(R_{e} ; d_{\mathrm{p}} / D ; l / D\right)$, column and material characteristics.

\section{STATISTICAL CONSIDERATIONS}

The parameters under study are $R_{\mathrm{e}}, d_{\mathrm{p}} / D$ and $l / D$ ratio. We will study the quantitative relation between the response UBZ and the three factors above, at three levels. A Box-Behnken design among the response surface designs will be applied in order to minimize the number of runs which are time and materials consuming (Otto, 1999). The factors' levels (high, mid and low) have been carefully chosen in order to conciliate practice and experimentations conditions in the limits of our material. The central point of the design has been displaced from the middle 0.00 to- 0.14 . The factors, as their respective coded levels, are listed in Table 3.

From the Box-Behnken design and the coded values of Table 3, we can draw the list of experimentations to be carried out (Table 4). Experimentation 13, according to the central point of the Box-Behnken design, has been repeated twice in order to evaluate experimental errors. Mean and standard deviation were calculated for this run.

The response surface method RSM allowed one to quantify and interpret the relationships between responses and factors' effects. This empirical second-order polynomial model is characterized by the following equation (Otto, 1999)

$$
y=b_{0}+\sum_{i=1}^{k} b_{i} x_{i}+\sum_{1 \leqslant i \leqslant j}^{k} b_{i j} x_{i} x_{j}+\sum_{i=1}^{k} b_{i i} x_{i}^{2},
$$

with $\mathrm{k}$ being the number of factors, $b_{0}$, the intercept parameter, $b_{\mathrm{i}} b_{\mathrm{ij}} b_{\mathrm{ij}}$, the regression parameters for linear, interaction and quadratic factor effects, $x_{i}$, the factors and $y$, the response.

Table 3. Factors and their respective levels.

\begin{tabular}{llll}
\hline Factors & \multicolumn{1}{l}{ Levels } & \\
\cline { 2 - 4 } & $\mathbf{- 1}$ & $\mathbf{0}$ & $\mathbf{+ 1}$ \\
\hline$L / D$ & 7.57 & 12.87 & 18.18 \\
$R_{\mathrm{e}}$ & 1.00 & 4.50 & 8.00 \\
$d_{\mathrm{p}} / D$ & 0.03 & 0.06 & 0.10 \\
\hline
\end{tabular}


Table 4. Runs to be achieved.

\begin{tabular}{lllll}
\hline Systematic run & Randomized & //D & $\boldsymbol{R}_{\mathbf{e}}$ & $\boldsymbol{d}_{\mathbf{p}} / \mathbf{D}$ \\
\hline 1 & 3 & +1 & +1 & -0.14 \\
2 & 9 & +1 & -1 & -0.14 \\
3 & 12 & -1 & +1 & -0.14 \\
4 & 2 & -1 & -1 & -0.14 \\
5 & 15 & +1 & 0 & +1 \\
6 & 4 & +1 & 0 & -1 \\
7 & 10 & -1 & 0 & +1 \\
8 & 6 & -1 & 0 & -1 \\
9 & 8 & 0 & +1 & +1 \\
10 & 14 & 0 & +1 & -1 \\
11 & 5 & 0 & -1 & +1 \\
12 & 1 & 0 & -1 & -1 \\
13 & 7 & 0 & 0 & -0.14 \\
14 & 11 & 0 & 0 & -0.14 \\
15 & 13 & 0 & 0 & -0.14 \\
\hline
\end{tabular}

\section{MATERIALS AND METHODS}

\subsection{Chemicals}

The metal ion studied was $\mathrm{Pb}^{2+}$ from a $10^{-3} \mathrm{M}$ solution of $\mathrm{Pb}\left(\mathrm{NO}_{3}\right)_{2},\left(207.2 \mathrm{mg} \mathrm{l} \mathrm{l}^{-1}\right.$ of $\left.\mathrm{Pb}^{2+}\right)$. A solution of $\mathrm{NaNO}_{3}, 0.5$ $\mathrm{M}$ was used as the pre-treatment solution. All chemicals used were of analytical grade from Merck Eurolab.

\subsection{Sorbent material}

The sorbent material used in this study was obtained from NZ Natural Zeolite, Zeotec Water, New Zealand. According to specifications, the mineral content was $75 \%$ pure clinoptilolite and mordenite and $25 \%$ of impurities such as Opal C1 and smectite. The specific gravity is $0.65 \mathrm{~g} / \mathrm{cm}^{3}$. Chemical composition of the material is listed in Table 5 .

The material was crushed and sieved to three different particle sizes: $0.65 \mathrm{~mm}(500 \mu \mathrm{m}<\Phi<800 \mu \mathrm{m}) ; 0.38 \mathrm{~mm}(250$ $\mu \mathrm{m}<\Phi<500 \mu \mathrm{m}) ; 0.20 \mathrm{~mm}(150 \mu \mathrm{m}<\Phi<250 \mu \mathrm{m})$; it was then washed to eliminate dust, dried at $103 \pm 2{ }^{\circ} \mathrm{C}$ for $16 \mathrm{~h}$, vacuumed to eliminate gas molecules from the pores and packed on the columns.

\subsection{Columns}

Glass columns of $0.66 \mathrm{~cm}$ internal diameter equipped with adjustable plungers for length control have been used within this study. Three different column lengths $5.00,8.50$ and $12.00 \mathrm{~cm}$ have been set.

\subsection{Pre-treatment}

Near homoionic $\mathrm{Na}$ form of the material was obtained in situ by passing through the column $50 \mathrm{BV}$ of $\mathrm{NaNO}_{3}$ solution at the flow rate of $\pm 7 \mathrm{BV} / \mathrm{h}$. The column was then rinsed in situ with $50 \mathrm{BV}$ of fresh distilled water at the same flow rate. 


\subsection{Experimental}

The flow rate $Q(\mathrm{ml} / \mathrm{min})$, was obtained from the linear velocity $(u)$ by the following equation. The linear velocity itself has been deduced from the previously fixed $R_{\mathrm{e}}$ as expressed by the value of $\pi 2$. The so-calculated $Q$ was delivered to the column by means of a Waters 515 HPLC volumetric pump. The effluent was automatically collected with a LKB Helirac 212 fraction collector in $20 \mathrm{ml}$ glass tubes.

$$
u=\frac{Q}{A^{\prime} n_{\mathrm{e}}}
$$

with $n_{\mathrm{e}}$, the effective porosity and $A^{\prime}$ the cross section of the column.

Table 5. Typical chemistry of the zeolite material.

\begin{tabular}{ll}
\hline $\mathrm{SiO}_{2}$ & $71.54 \%$ \\
$\mathrm{Al}_{2} \mathrm{O}_{3}$ & $18.44 \%$ \\
$\mathrm{~K}_{2} \mathrm{O}$ & $2.66 \%$ \\
$\mathrm{CaO}$ & $1.75 \%$ \\
$\mathrm{Na}_{2} \mathrm{O}$ & $1.74 \%$ \\
\hline
\end{tabular}

\subsection{Analytical}

Samples were acidified with $1 \mathrm{ml}$ of $\mathrm{HCl} 2 \mathrm{M}$ and analyzed for Pb content by a Metrohm Herissau E 502 polarograph. Six $\mathrm{ml}$ of acidified samples $(0.1 \mathrm{M} \mathrm{HCl})$ was placed in the cell and analyzed in differential pulse mode $(50 \mathrm{mV}$ pulse, with linear potential variation of $3 \mathrm{mV} / \mathrm{s}$ ) from -0.2 to $-0.6 \mathrm{~V}$. The lead peak maximum appears at $-0.38 \mathrm{~V}$ ( $\mathrm{vs}$. $\mathrm{Ag} / \mathrm{AgCl}$, saturated $\mathrm{KCl})$. The LOQ was established at $10^{-8} \mathrm{M}$ in pulse mode.

\section{RESULTS}

Results for UBZ and corresponding cationic exchange capacity (CEC) are numerated in Table 6. Here, we are referring to CEC as the operating capacity, the one obtained by an operator in specific given conditions. Inglezakis et al. (2002) have defined it as maximum exchange level (MEL).

\subsection{Interpretation}

The experimental error is calculated on the basis of three repetitions of the center point of the design (runs 13, 14 and 15). It is expressed by the standard deviation of 0.015 , as shown in Table 6. Results obtained from Minitab Inc. (2003) for a complete quadratic model ihowed that the main effects are significant ( $p$-value $1 / D=0.013, p$-value $R_{\mathrm{e}}=0.004$ and $p$-value $\left.d_{\mathrm{p}} / D=0.006\right)$. The UBZ response from the coded level parameters with a residual standard deviation of 0.041 and an $R^{2}$ of $93.5 \%$ is given by

$$
\begin{aligned}
\mathrm{UBZ}= & 0.22850-0.05450^{l^{*} / D}+0.07213^{R_{\mathrm{e}}^{*}} \\
& +0.06637^{d_{\mathrm{p}}^{*} / D}+0.04192^{\left(l^{*} / D\right)^{2}}-0.02083^{\left(R_{\mathrm{e}}^{*}\right)^{2}} \\
& -0.02741^{\left(d_{\mathrm{p}}^{*} / D\right)^{2}}+0.03725^{\left(l^{*} / D\right) R_{\mathrm{e}}^{*}} \\
& -0.03035^{\left(l^{*} / D\right)\left(d_{\mathrm{p}}^{*} / D\right)}+0.03400^{R_{\mathrm{e}}^{*} d_{\mathrm{p}}^{*} / D}
\end{aligned}
$$

with $l^{*} / D, R_{e}^{*}, \mathrm{~d}_{\mathrm{p}}^{*} / D$ the coded levels of parameters related to Table 2 .

The $\mathrm{F}$ test has been performed to evaluate the model; the ratio of lack-of-fit and the pure error gave a $p$-value of 0.079 , which was not significant. That revealed the model satisfactorily.

The response surface is plotted for the minimum level of $l^{*} / D$ in Fig. 1.

Eq. (5) allowed drawing contour curves of UBZ vs. $d_{\mathrm{p}}{ }^{*} / D$ and $R_{e}{ }^{*}$ for different fixed levels of the column geometry, which was the easiest parameter to be set from a practical point of view. 
Published in: Water research (2005), vol. 39, iss. 16, pp. 4004-4010 Statut: Postprint (Author's version)

Table 6. Results for UBZ and CEC

\begin{tabular}{|c|c|c|c|}
\hline & Run & UBZ & $\operatorname{CEC}(g / g)$ \\
\hline & 3 & 0.348 & 0.107 \\
\hline & 4 & 0.227 & 0.106 \\
\hline & 5 & 0.229 & 0.103 \\
\hline & 6 & 0.143 & 0.103 \\
\hline & 7 & 0.403 & 0.101 \\
\hline & 8 & 0.197 & 0.103 \\
\hline & 9 & 0.320 & 0.105 \\
\hline & 10 & 0.124 & 0.102 \\
\hline & 11 & 0.160 & 0.103 \\
\hline & 12 & 0.117 & 0.104 \\
\hline & 13 & 0.235 & 0.105 \\
\hline & 14 & 0.206 & 0.104 \\
\hline & 15 & 0.215 & 0.101 \\
\hline Mean & & 0.219 & 0.103 \\
\hline SDT & & 0.15 & 0.02 \\
\hline
\end{tabular}

Fig. 1. Response surface for $l / D$ at minimum level.

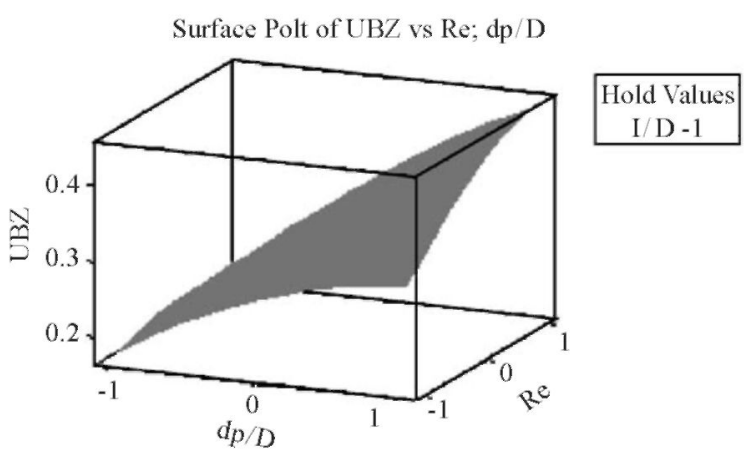




\section{DISCUSSION}

At first sight, it is noticed that the operating exchange capacity presented herein (CEC) did not change for different experiments, as this has been already stated elsewhere (Lieu and Weber 1981; Helfferich, 1995): the operating capacity of a given zeolite for a given pollutant in single component ion exchange is constant whatever the conditions applied to the operations. Some authors reached the opposite conclusion, which says that the operating capacity of zeolite varies according to operating conditions such as flow rate or particle size (Inglezakis and Grigoropoulou, 2004).

Contour plots drawn from Eq. (5) are of great importance for the designer to optimize his reactor performances. Performance is expressed as UBZ values, the lower the better. A low UBZ implies maximal use of the material.

As shown in Figs. 2-4, the range inside which experimental values have been chosen for the parameters made it possible to lower the UBZ to $10 \%$ of the total operating capacity; this means that it was possible to reach a maximum of $90 \%$ of the surface of the material available for exchange from a given combination of the parameters. In fact, it is possible to reach lower values for UBZ. The lower left corners of the figures represent the absolute minimum of 5.6\% for UBZ with the following coordinates $\left(l^{*} / D, R_{e}{ }^{*}, d_{\mathrm{p}}{ }^{*} / D\right)=(+1,-1,-1)$ at coded levels and $(18.18 ; 1 ; 0.03)$ at real values. This point is of great importance. Indeed, it unambiguously determines the operating parameters leading to maximum efficiency of the system $(94.4 \%)$. It is also noteworthy that the model is more precise in the area close to the center, which corresponds to conditions similar to those of the run 13 with an UBZ around $20 \%$.

Fig. 2. Contour plot of $U B Z$ vs $d_{p}{ }^{*} / D ; R_{e}^{*}$ for $l^{*} / D$ at level -1 .

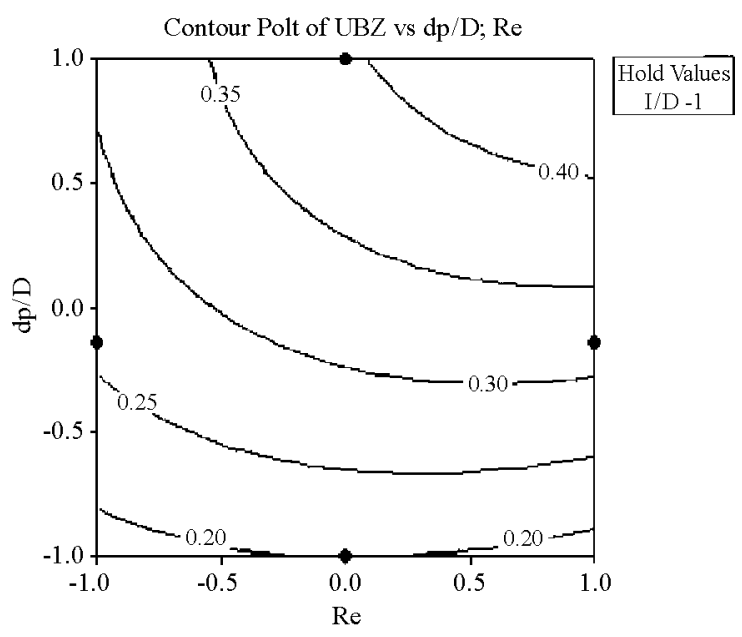

Fig. 3. Contour plot of UBZ vs. $d_{p}{ }^{*} / D ; R_{e}{ }^{*}$ for $l^{*} / D$ at level 0 .

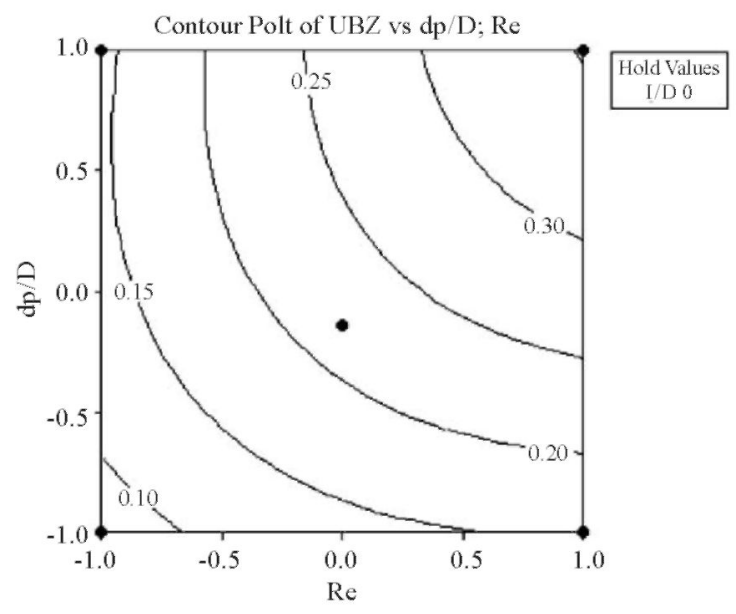


Fig. 4. Contour plot of UBZ vs. $d_{p}{ }^{*} / D ; R_{e}{ }^{*}$ for $l^{*} / D$ at level +1 .



On the other hand, one decides to operate at an efficiency of $10 \%$ for UBZ, once the column geometry is chosen, (for instance $l / D=1)$. Fig. 4 shows how wide the range inside which he can choose the particle sizes according to $d_{\mathrm{p}} / D$, from $3 \%$ to $10 \%$, meanwhile the $R_{e}$ range diminished and is between -0.5 and -1 (real values: 1 and 2.75). The flexibility to choose the particle diameter is important as finer particles could be avoided. The reason is both economic (as finer crushing involves higher cost) and technical (as excessive head losses caused by finer particles can be avoided inside the reactor).

Finally, contour curves represent a very important tool for the designer; once he has set one of the parameters, his column geometry for instance, he can use the proper corresponding contour curve to set the other parameters, in order to perform a better operation for a given operating capacity of his material. If the operator's aim is not to design but to evaluate the performance of an operating reactor, he may use the following equation. This equation has been deduced from the same experiment, by substituting coded values of the parameters for the real ones.

$$
\begin{aligned}
\mathrm{UBZ}= & 0.32239-0.04707^{l / D}+0.00796^{R_{\mathrm{e}}} \\
& +5.71431^{d_{\mathrm{p}} / D}+0.00149^{I^{2} / D}-0.0017^{R_{\mathrm{e}}^{2}} \\
& -22.84167^{d_{\mathrm{p}}^{2} / D}+0.00201^{(l / D) R_{\mathrm{e}}} \\
& -0.16292^{(l / D)\left(d_{\mathrm{p}} / D\right)}+0.27755^{R_{\mathrm{e}} d_{\mathrm{p}} / D}
\end{aligned}
$$

With $l / D, R_{e}, d_{\mathrm{p}} / D$ the real values of the parameters related to table 3 .

The validity domain of Eq. 6 is: $1<R_{e}<8 ; 7<l / D<20 ; 0.03<d_{\mathrm{p}} / D<0.1$.

\section{CONCLUSION}

Results found in the present work are in line with those of Inglezakis and Grigoropoulou, (2004); Nastro and Colella, (1983) who suggested some improvements for better operation performance. The advantage of this work has been to graphically summarize the dispersed recommendations, making it of practical and easier use. Moreover, this study established a mathematical relation predicting the performance of a single component ion exchange operation in a fixed-bed reactor. Furthermore, the equation being drawn from dimensionless values of the flow parameters, column geometry and particle characteristics should give an excellent way to shift from laboratory scale experiments to pilot scale reactors. The $R_{e}$ range covers laminar flow conditions from 1 to 8 ; the column geometry expressed as the ratio $l / D$ can be extended from 7 to 20 and the particle characteristics as the ratio $d_{\mathrm{p}} / D$ varies from $3 \%$ to $10 \%$. Optimization of performance of the reactor, expressed as the unused bed zone, could be lowered from $40 \%$ to less than $10 \%$ of the total operating capacity of the material. Optimum values are reached for $l / D$ chosen close to 1 (20); with a large amplitude for $d_{\mathrm{p}} / D$ over the whole range, and a smaller one for $R_{e}$ comprised roughly between -0.5 and - 1 . ( 1 and 2.75). In a complimentary approach, the ongoing study will be extended to other materials and heavy metal cations alone or in combinations. However, this model should be valuable for any single component ion exchange under study. What 
changes is the operating capacity, which may differ for a given cation of a given material, but the model can still predict the performance of reactors from the applied operating conditions and, for the case of designing purpose, it can help find the accurate combination of parameters to achieve a given goal. Finally, this model compared to others points out the advantage of being easy to use and free of highly complicated mathematical relations. In spite of being empiric, it is very convenient to situations where complicated mathematical models are of lower importance.

\section{Acknowledgements}

The authors would like to acknowledge Coopération Universitaire au Développement (CUD) and the Agence Universitaire de la Francophonie (AUF) for their financial support; Doctor Inglezakis VJ, for his help in providing documentation; the Department of Statistics of Gembloux University and finally Piscart Fabienne, Taziaux Jean, Sprangers Olivier.

\section{References}

Bear, J., 1972. Dynamics of Fluids in Porous Media. Elsevier, New York, pp. 579-663 (Chapter 10).

Chen, P.J., Wang, L., 2004. Characterization of metal adsorption kinetic properties in batch and fixed-bed reactors. Chemosphere 54 (3), $397-404$.

Crittenden, J.C., Weber, W.J., 1978. Predictive model for design of fixed-bed absorbers: single-component model verification. J. Environ. Eng. Div. 104, 433-443.

Daugherty, L., Franzini, B., Finnemore, John, E., 1985. Fluid Mechanics with Engineering Applications, eighth ed. McGraw-Hill, New York, pp. 119193 (Chapter 5).

Guo-Hua, Xiu., Ping, Li., 2000. Prediction of breakthrough curves for adsorption of lead(II) on activated carbon fibers in a fixed bed. Carbon 38 (7), 975-981.

Hashimoto, K., Miura, K., Tsukano, M., 1977. Experimental verification of design methods for liquid phase fixed bed absorbers. J. Chem. Eng. Jpn. $10,27-34$

Helfferich, F., 1995. In: Ion Exchange. Dover Publications Inc., New York, p. 421.

Hlaway, J., Vigh, G., Olaszi, V., Inczedy, J., 1982. Investigations on natural Hungarian zeolite for ammonia removal. Water Res. 16, 417-420.

Inczédy, J., 1966. Analytical Applications of Ion Exchangers. Akadémiai Kiadó, Budapest, pp. 1-80.

Inglezakis, V.J., Grigoropoulou, H., 2001. Applicability of simplified models for the estimation of ion exchange diffusion coefficients in zeolites. J. Colloid. Interface Sci. 234, 434-441.

Inglezakis, V.J., Loizidou, M.D., Grigoropoulou, H., 2002. Equilibrium and kinetic ion exchange studies of $\mathrm{Pb}^{2+}, \mathrm{Cr}^{3+}, \mathrm{Fe}^{3+}$ and $\mathrm{Cu}^{2+}$ on natural clinoptilolite. Water Res. 36, 2784-2792.

Inglezakis, V.J., Grigoropoulou, H., 2003. Modeling of ion exchange of $\mathrm{Pb}^{2+}$ in fixed beds of clinoptilolite. Microporous Mesoporous Mater. 61 (1-3), 273-282.

Inglezakis, V.J., Grigoropoulou, H., 2004. Effects of operating conditions on the removal of heavy metals by zeolite in fixed bed reactors. J. Hazard. Mater. B 112, 37-43.

Iordanidis, A.A., Van Sint Annaland, M., Kronberg, A.E., Kuipers, J.A.M., 2003. A critical comparison between the wave model and the standard dispersion model. Chem. Eng. Sci. 58 (13), 2785-2795.

Lau, A., Crittenden, B.D., Field, R.W., 2004. Enhancement of liquid phase adsorption column performance by means of oscillatory flow: an experimental study. Separat. Purificat. Technol. 35 (2), 113-124.

Lieu, K.T., Weber, W.J., 1981. J. WPCF 53, 1541.

Minitab Inc. 2003. MINITAB statistical software, Release 14 for Windows, State College, Pennsylvania.

Miyake, Y., Suzuki, M., 1993. Removal of trichloroethylene from air stripping off-gas by adsorption on activated carbon fibre. Gas Separat. Purificat. 7, 229-234.

Nastro, A., Colella, C., 1983. Column ion exchange data for ammonium removal water by phillipsite tuff. Ing. Chim. Ital. 19 (5-6), $41-45$.

Otto, M., 1999. Chemometrics: Statistics and Computer Application in Analytical Chemistry. Weinheim, New York, pp. 81-117 (Chapter 4).

Ouziaux, R., Perrier, J., 1978. Mécanique des Fluides Appliquée, third ed. Dunod University, Bordas, Paris, pp. 448-525.

Pansini, M., 1996. Natural zeolites as cation exchangers for environmental protection. Miner. Deposita 31, 563-575.

Suzuki, M., 1990. Adsorption Engineering. Elsevier, Amsterdam, pp. 180-190; 63-67.

Suzuki, M., 1994. Activated carbon fiber: fundamentals and applications. Carbon 32, 577-586.

Zorpas, Antonis A., Inglezakis, V.J., Loizidou, M., Grigoropoulou, H., 2002. Particle size effects on uptake of heavy metals from sewage sludge compost using natural zeolite clinoptilolite. J. Colloid. Interface Sci. 250, 1-4. 